\title{
"SEPARAÇÃO E IDENTIFICAÇÃO DE CORANTES SINTÉTICOS PARA FINS ALIMENTÍCIOS SOLÚVEIS EM ÁGUA"
}

\author{
KEIKO TAKASHIMA ${ }^{a}$ \\ NEIDE HIROKO TAKATA ${ }^{b}$ \\ WILSON MITSUO NAKAMURA ${ }^{\mathrm{b}}$
}

\section{RESUMO}

Descrição da extração de corantes sintéticos permitidos para fins alimentícios pela técnica do fio de lã sua separação e identificação por cromatografia em papel e espectrofotometria UV-VIS em amostras de gelatinas e refrescos em pó de diversos sabores e marcas e anilinas para bolo.

PALAVRAS-CHAVE: Corantes; Corantes para fins alimentícios; Cromatografia em papel.

\section{INTRODUÇÃO}

As indústrias alimentícias e de bebidas utilizam grande quantidade de corantes com a finalidade de reter a aparência do material original e tornar os produtos mais atrativos. Os alimentos e bebidas podem ser coloridos por corantes orgânicos sintéticos, pigmentos inorgânicos e materiais naturais obtidos a partir de fontes vegetais e animais. Destes, os de origem orgânica sintética são geralmente os mais utilizados por serem dotados de um intervalo amplo de cores e um poder tintorial e brilho uniformes. Estes corantes são empregados muitas vezes para substituir substâncias nutritivas tais como carotenóides e riboflavinas, mas do ponto de vista nutricional além de não acrescentarem nada, muitos são tóxicos e carcinogênicos ${ }^{7,8}$.

Dentre os corantes artificiais, os azo-compostos proporcionam grande importância na indústria de corantes, devido a coloração intensa, a estabilidade e a possibilidade de síntese a partir de substâncias de baixo custo. Os derivados de azo-benzeno mais simples apresentam normalmente uma coloração amarela ou amarelo-alaranjada, em virtude da conjugação na ligação formada pelo grupo azo, $-\mathrm{N}=\mathrm{N}-\mathrm{e}$ os dois anéis aromáticos e possuem, pelo menos, um grupo sulfonato para aumentar a solubilidade em água. Como a maioria dos corantes possui diversas denominações e estruturas relativamente complexas, são sistematicamente descritos pelos números de C.I. (Color Index) e/ou F.D. \& C (Food, Drug \& Cosmetics Act.). ${ }^{2}$ $\mathrm{Na}$ Tabela I são apresentados alguns corantes com seus números de C.I. e os países em que são permitidos ${ }^{3,4,6}$. Como pode ser observado nesta Tabela, a relação de corantes permitidos difere grandemente de um país para o outro, devido às controvérsias geradas em torno da toxidez deste ou daquele corante. Pela Resolução Normativa n. 5/78 aprovada pela Câmara Técnica de Alimentos do Conselho

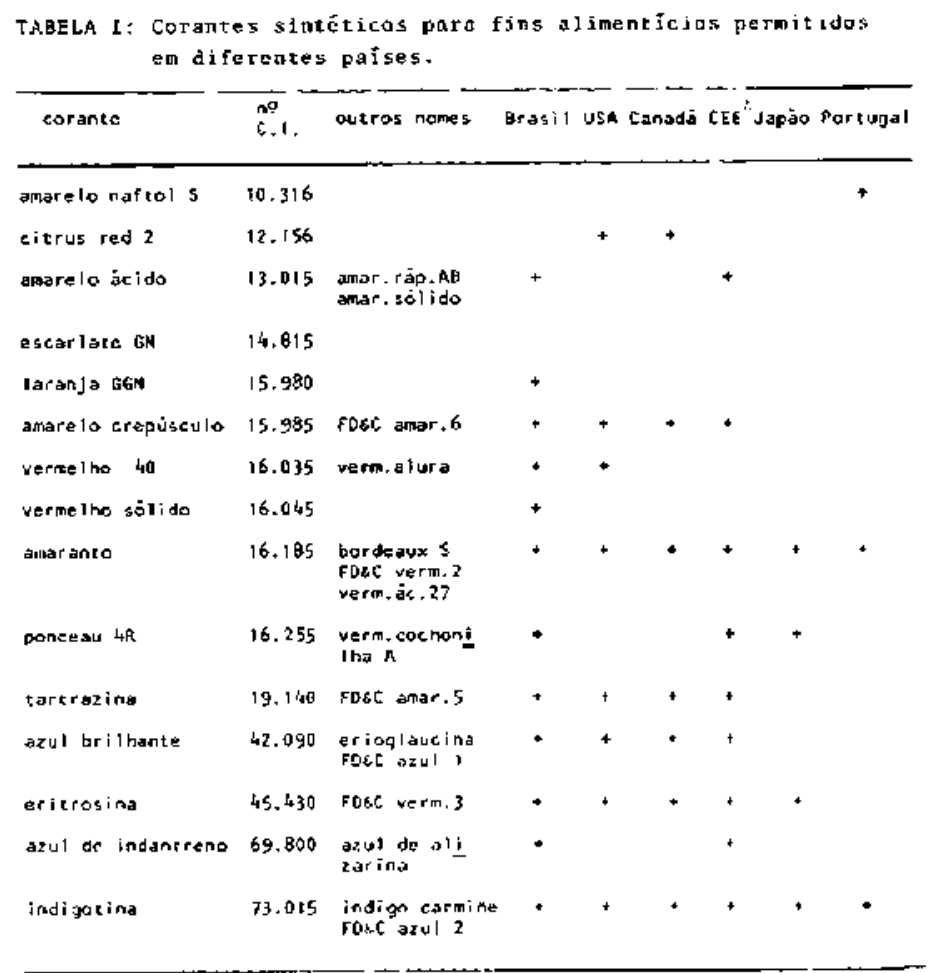

$\therefore$ Palses da Lestunldade Econginic ca Europétio

Nacional de agosto de 1978, o citrus red n. 2 (C.I. 12.156) e o escarlate GN(CI. 14.815) permitidos até então, passaram a ser proibidos. Atualmente são doze os corantes sintéticos solúveis em água permitidos no Brasil. Destes, sete (amaranto, ponceau 4R, vermelho sólido, laranja GGN, amarelo ácido, amarelo crepúsculo e vermelho 40) 
pertencem ao grupo azo-sulfona; a tartrazina é uma pirazolona, a eritrosina é um xanteno, o azul brilhante um trifenilmetano, a indigotina um indigóide e finalmente o azul de indantreno, uma antraquinona. A dosagem máxima $(0,01 \%)$ destes corantes em alimentos é regulamentada pela Resolução n. 44/77 da Comissão Nacional de Normas e Padrões para Alimentos.

De modo geral, não é possível identificar diretamente os corantes contidos em gêneros alimentícios. Eles devem ser extraídos, purificados e concentrados antes da identificação. Este trabalho tem como objetivo a extração de corantes de amostras de gelatinas e refrescos em pó de diversas marcas e sabores e de anilinas para bolo e sua separação e identificação através da cromatografia em papel e espectrofotometria UV-VIS.

\section{2 - MATERIAIS E MÉTODOS}

a) Extração de corantes das amostras.

A extração foi feita dissolvendo-se de 10 a $15 \mathrm{~g}$ de amostra em $100 \mathrm{ml}$ de água deionizada e acidificando-se com 5 gotas de ácido acético glacial. A $35 \mathrm{ml}$ desta solução foi adicionado um fio de lã branca de $20 \mathrm{~cm}$ (previamente fervido em solução de hidróxido de sódio e depois em água) e fervida por alguns minutos. O fio de lã branca foi retirado, lavado com água, transferido para um pequeno béquer e fervido em $20 \mathrm{ml}$ de amoníaco a $10 \%$. O fio de lã foi retirado e a solução evaporada até um volume de $\sim 1 \mathrm{ml}^{5}$. Para os corantes alimentícios em pó e em solução não foi realizada esta etapa.

b) Separação e identificação de corantes extraídos.

Os corantes extraídos foram separados por cromatografia em papel, técnica ascendente 6 . Os corantes de referência utilizados neste trabalho (Tabela II) e os extraídos foram aplicados (5mL por amostra) sobre o papel Whatman no. 1 (Klabin) em diversos sistemas de solventes (Tabela III).

Um outro método de identificação foi realizado pela análise espectrofotométrica (espectrofotômetro Shimadzumod.UV-100-02), dissolvendo-se os corantes em meio ácido (HC1 0,1 M), básico $(\mathrm{NaOH} 0,1 \mathrm{M})$ e neutro (acetato de amônio $0,02 \%)$.

\section{RESULTADOS E DISCUSSÃO}

Os corantes incorporados nos produtos analisados tiveram boas recuperações para os corantes estudados com exceção da indigotina, que foi impossível porque se decompõe em soluções alcalinas ${ }^{1}$.

Os valores de $R f$ medidos para os corantes de referência e os extraídos de gêneros alimentícios em diversos sistemas de solventes são mostrados na Tabela IV. A separação de corantes por cromatografia em papel não apresenta resolução desejada, mas possui a vantagem de ser um método

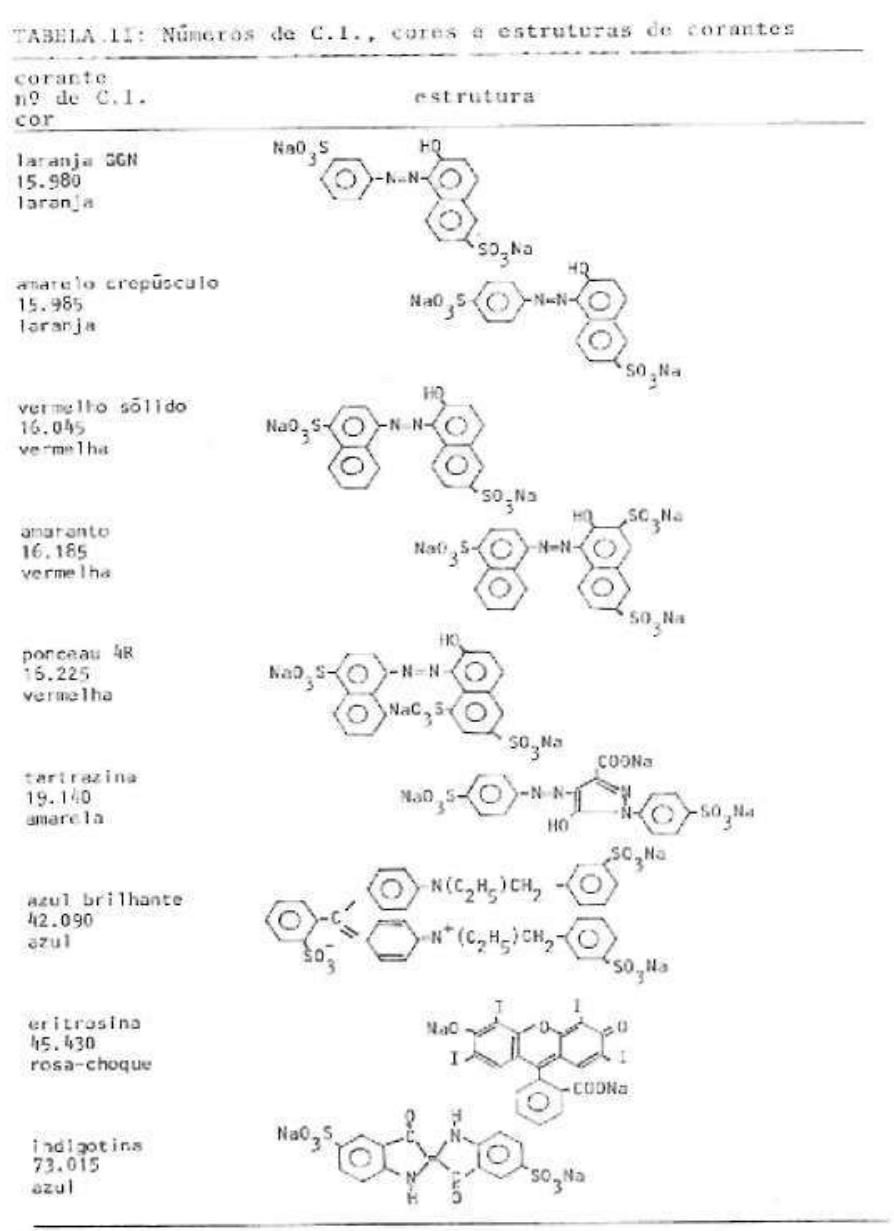

\begin{tabular}{|c|c|c|}
\hline solvente & composisào & ref. \\
\hline 1 & iso-butano]-ttanol-ägua-ameníaco[ $[50: 35: 25:(y)$ ). & - \\
\hline 2 & $y \operatorname{mon} i \operatorname{sco}(0,88)-a ́ g u a(1: 99)$ & 6 \\
\hline 3 & ת-butano1-igua-je. ucético g) acial $(20: 12: 5)$ & 6 \\
\hline 4 & Nitcl z: en etanol 50i & 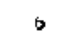 \\
\hline $\mathbf{s}$ & n-ргораnoj-amon íaco $(0,88)-$ igua $160: 2: 32$ ) & - \\
\hline 6 & Nas: 25 & $\dot{0}$ \\
\hline$?$ & feno)-ägua ( $80 \mathrm{~g}-3 \| \mathrm{l})$ & Ğ \\
\hline
\end{tabular}

de baixo custo, rápido e relativamente simples para determinações qualitativas. Dos sistemas de solventes utilizados, o que apresentou melhores resultados foi o n-propanolamoníaco-água (66:2:32) pois o arraste quando comparado com os outros foi menor e as separações bem mais definidas. 
TABELA IV: Valores de $R_{f}$ aproxinados de corantes em diferentes sistemas de solventes.

\begin{tabular}{|c|c|c|c|c|c|c|c|}
\hline \multirow{2}{*}{ corante } & \multicolumn{7}{|c|}{ solvente } \\
\hline & 1 & 2 & 3 & 4 & 5 & 6 & 7 \\
\hline laranja GON & 0,60 & 0,96 & 0,42 & 0,52 & 0,75 & 0,17 & 0,45 \\
\hline anax +cremiscula & 0,64 & 0,94 & 0,36 & 0,68 & 0,68 & 0,25 & 0,51 \\
\hline taxtrazina & 0,21 & 0,95 & 0,02 & 0,54 & 0,50 & 0,32 & 0,18 \\
\hline verm. sö1ido & 0,63 & 0.84 & 0.43 & 0,27 & 0.73 & 0,06 & 0,50 \\
\hline amaranto & 0,33 & 0,92 & 0,12 & 0.33 & 0,49 & 0,13 & 0.17 \\
\hline ponceat $4 \mathrm{R}$ & 0,35 & 0,98 & 0,09 & $0,+8$ & 0,54 & 0,30 & 0,17 \\
\hline eritrosina & 0,80 & 0,59 & 0.94 & 0,60 & 0,86 & 0,02 & 0,52 \\
\hline azul brilhante & 0,50 & 0,96 & 0,48 & 0,94 & 0,79 & 0,69 & 0,75 \\
\hline azul indigotina & 0,21 & 0,94 & 0,48 & 0,21 & 0.53 & 0,10 & 0,42 \\
\hline anar.ouro(Gol rinhe) & 0,95 & 0,45 & $0,8 \mathrm{~S}$ & 0,63 & 0,97 & 0,05 & 0,88 \\
\hline vermeltwo (Golfitho) & 0,97 & 0,18 & 0,00 & -- & 0,98 & 0,10 & -- \\
\hline rosa (Golfinha) & 0,97 & 0,18 & 0,00 & -- & 0,48 & 0,10 & -- \\
\hline
\end{tabular}

Os corantes extraídos das diversas amostras estudadas estão representadas na Tabela V. Por meio desta Tabela pode ser observado que o corante mais comumente utilizado em alimentos de coloração vermelha é o amaranto; a tartrazina e o amarelo crepúsculo foram encontrados em amostras de coloração amarela ou alaranjada. $O$ verde é obtido pela mistura de tartrazina e azul brilhante. A indigotina foi detectada apenas no verde-folha da San-ei porque foi usado sem tratamento preliminar com amoníaco. ${ }^{1}$ Nos corantes rosa, vermelho e amarelo-ouro encontrados no mercado como anilinas para bolo (Golfinho) não foram detectados nenhum dos corantes estudados neste trabalho. As absorções máximas dos corantes em meio ácido, básico e neutro são mostradas na Tabela VI. Conforme pode ser verificado nesta Tabela, as absorções das anilinas não coincidem com nenhum dos valores dos padrões estudados.

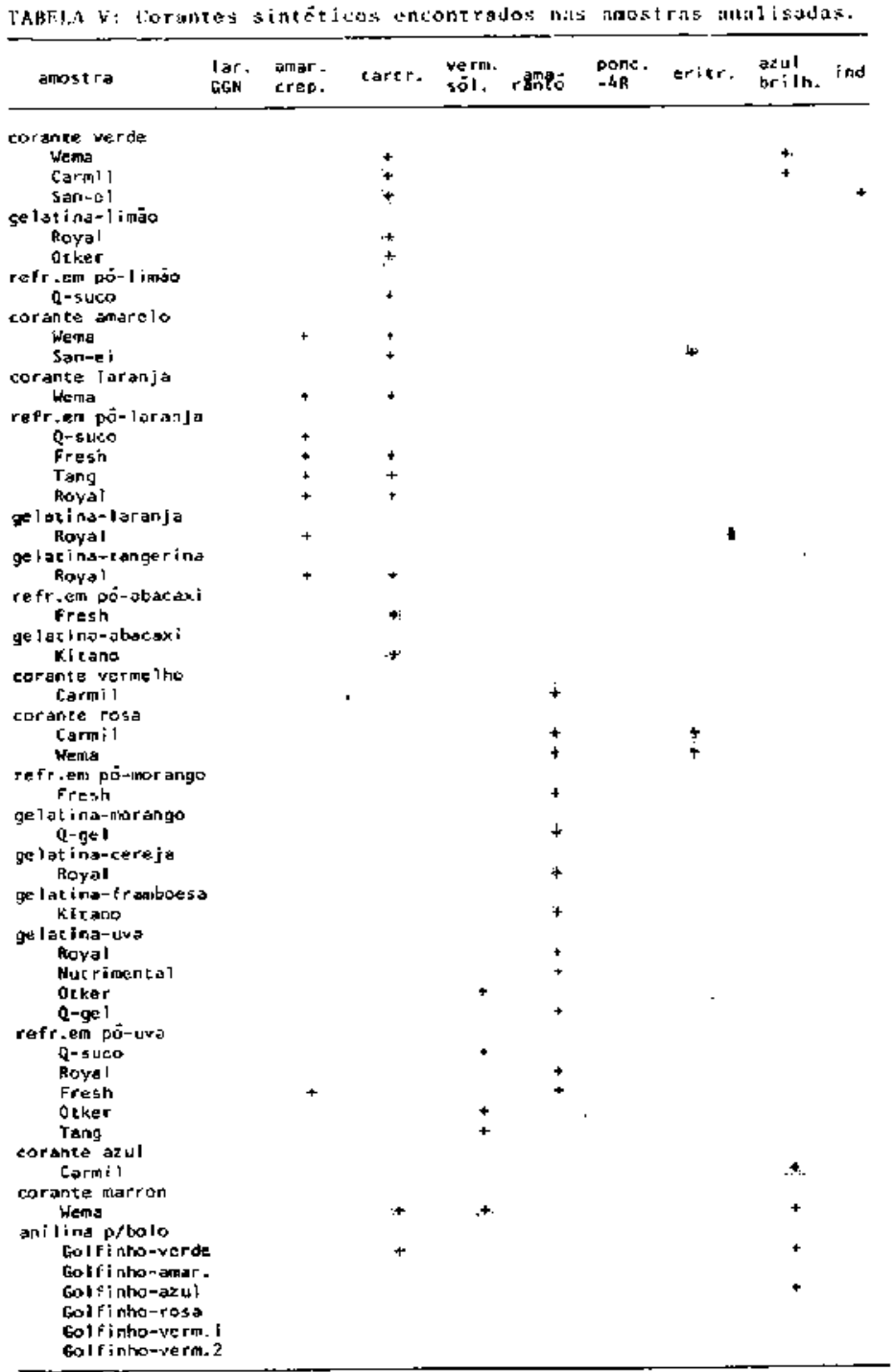

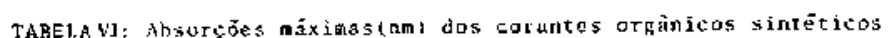
estudados.

\begin{tabular}{|c|c|c|c|}
\hline \multirow{2}{*}{ coralite } & \multicolumn{3}{|c|}{ neio } \\
\hline & 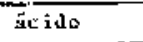 & neutro & bissco \\
\hline Laranja GGN & 480 & $4 \mathrm{so}$ & 434 \\
\hline anare lo creyisculo & $\$ 87$ & $48: 2$ & 145 \\
\hline tarerazing & 430 & $43 \mathrm{~s}$ & 405 \\
\hline verme the sollido & $\operatorname{sog}$ : & 505 & 470 \\
\hline amstunto & $\$ 20:$ & 525 & 490 \\
\hline pancesus $4 R$ & 507 & 507 & 437 \\
\hline exitrosing & insolüvel & 527 & $52 \frac{1}{7}$ \\
\hline gatul briinante & 630 & 690 & 63 \\
\hline azul indigotinu & 610 & 610 & 40 \\
\hline umarelo ouro(Colfinto) & 525 & 438 & 4.38 \\
\hline verme 1 ho(Golfinho) & $\$ 58$ & 554 & $s \$$ \\
\hline rosu(bolfinho) & 558 & 554 & 554 \\
\hline
\end{tabular}




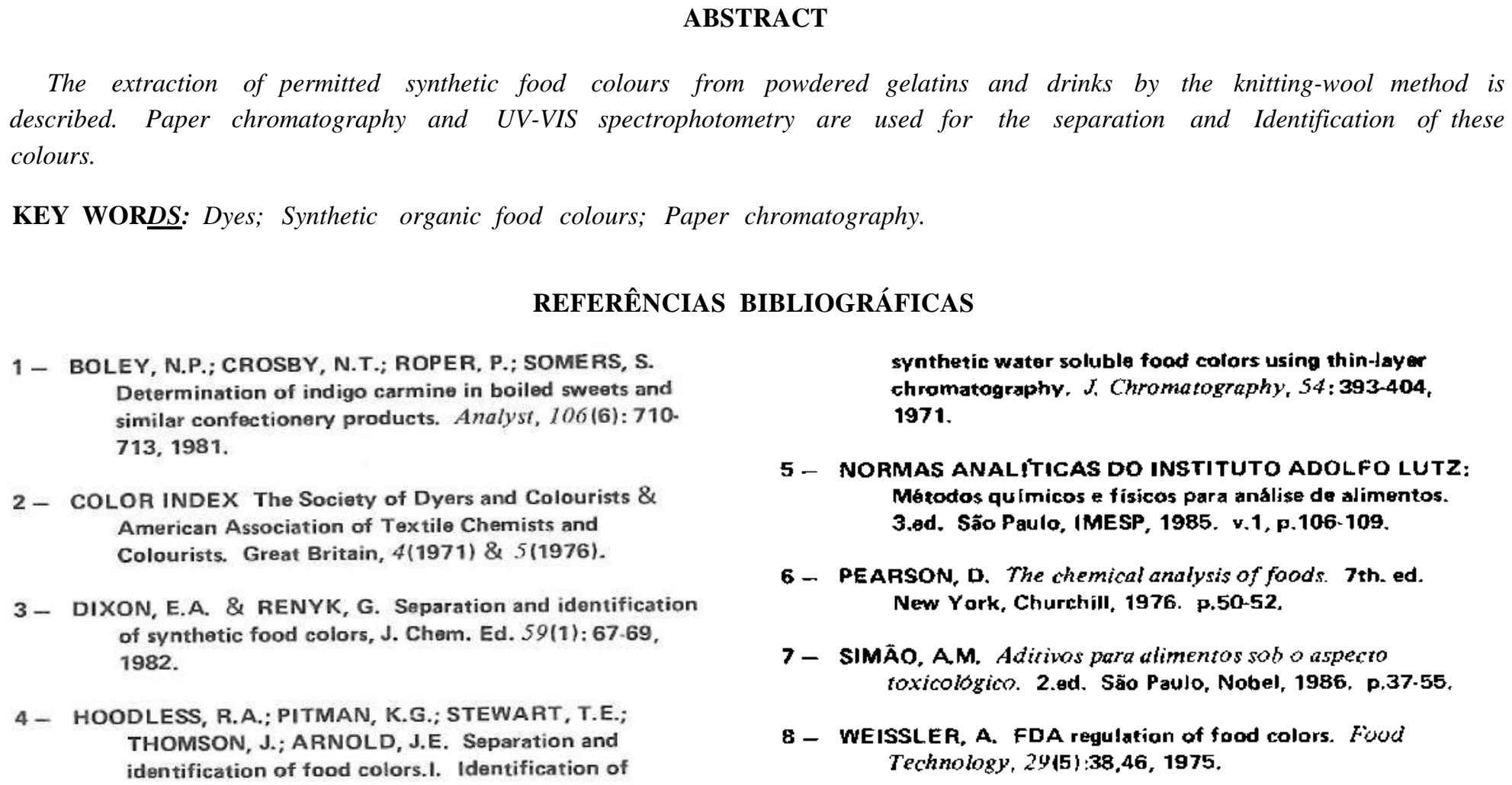

The extraction of permitted synthetic food colours from powdered gelatins and drinks by the knitting-wool method is described. Paper chromatography and UV-VIS spectrophotometry are used for the separation and Identification of these colours.

KEY WORDS: Dyes; Synthetic organic food colours; Paper chromatography.

\section{REFERÊNCIAS BIBLIOGRÁFICAS}

1 - BOLEY, N.P.; CROSBY, N.T.; ROPER, P.; SOMERS, S. Determination of indigo carmine in boiled sweets and similar confectionery products. Analyst, 106(6): 710 . 713, 1981.

2 - COLOR INDEX The Society of Dyers and Colourists \& American Association of Textile Chemists and Colourists. Great Britain, 4(1971) \& 5(1976).

3 - DIXON, E.A. \& RENYK, G. Separation and identification of synthetic food colors, J. Chem. Ed. 59(1):67.69, 1982.

4 - HOODLESS, R.A.; PITMAN, K.G.; STEWART, T.E.; THOMSON, J.; ARNOLD, J.E. Separation and identification of food colors.I. Identification of

synthetic water soluble food colors using thin-layer chromatography, J, Chromatography, 54:393-404, 1971.

5 - NORMAS ANALITICAS DO INSTITUTO ADOLFO LUTZ: Métodos químicos e fisicos para análise de alimentos. 3.ed. São Paulo, IMESP, 1985. v.1, p.106.109.

6 - PEARSON, D. The chemical analysis of foods. 7th. ed. New York, Churchill, 1976. p.50-52.

7 - SIMÄo. A.M. Aditinos para alimentos sob o aspecto toxicologico. 2.ed. São Paulo, Nobel, 1986, p,37-55.

8 - WEISSLER, A. FDA regulation of food colors. Food Technology, 29(5):38,46, 1975.

Recebido para publicaçäo em 27/08/87 